\title{
REVIEWS
}

\section{Impact of Interventions to Increase the Proportion of Medical Students Choosing a Primary Care Career: A Systematic Review}

\author{
Eva Pfarrwaller, M.D. ' , Johanna Sommer, M.D. ${ }^{\text {, }, ~ C h r i s t o p h e r ~ C h u n g, ~ M . D . ~}{ }^{\text {, }}$ \\ Hubert Maisonneuve, M.D. ${ }^{7}$, Mathieu Nendaz, M.D., M.H.P.E. ${ }^{2}$, Noëlle Junod Perron, M.D. , Ph.D. ${ }^{3}$, \\ and Dagmar M. Haller, M.D., Ph.D. ${ }^{1}$

\begin{abstract}
'Primary Care Unit, Faculty of Medicine, Centre Médical UniversitaireUniversity of Geneva, Genève 4, Switzerland; ${ }^{2}$ Unit of Development and Research in Medical Education, Faculty of MedicineUniversity of Geneva, Geneva, Switzerland; ${ }^{3}$ Division of primary care medicineGeneva University Hospitals, Geneva, Switzerland.
\end{abstract}

\begin{abstract}
BACKGROUND: Increasing the attractiveness of primary care careers is a key step in addressing the growing shortage of primary care physicians. The purpose of this review was to (1) identify interventions aimed at increasing the proportion of undergraduate medical students choosing a primary care specialty, (2) describe the characteristics of these interventions, (3) assess the quality of the studies, and (4) compare the findings to those of a previous literature review within a global context.
\end{abstract}

METHODS: We searched MEDLINE, EMBASE, ERIC, CINAHL, PsycINFO, The Cochrane Library, and Dissertations \& Theses A\&I for articles published between 1993 and February 20, 2015. We included quantitative and qualitative studies reporting on primary care specialty choice outcomes of interventions in the undergraduate medical curriculum, without geographic restrictions. Data extracted included study characteristics, intervention details, and relevant outcomes. Studies were assessed for quality and strength of findings using a five-point scale.

RESULTS: The review included 72 articles reporting on 66 different interventions. Longitudinal programs were the only intervention consistently associated with an increased proportion of students choosing primary care. Successful interventions were characterized by diverse teaching formats, student selection, and good-quality teaching. Study quality had not improved since recommendations were published in 1995. Many studies used cross-sectional designs and non-validated surveys, did not include control groups, and were not based on a theory or conceptual framework.

DISCUSSION: Our review supports the value of longitudinal, multifaceted, primary care programs to increase the proportion of students choosing primary care specialties. Isolated modules or clerkships did not appear to be effective. Our results are in line with the conclusions from previous reviews and add an international perspective, but the evidence is limited by the overall low methodological quality of the included studies. Future research should use more rigorous evaluation methods and include long-term outcomes.

Electronic supplementary material The online version of this article (doi:10.1007/s11606-015-3372-9) contains supplementary material, which is available to authorized users.

Published online July 15, 2015
KEYWORDS: Medical education-undergraduate; Primary care; Systematic reviews; Workforce.

J Gen Intern Med 30(9):1349-58

DOI: $10.1007 / \mathrm{s} 11606-015-3372-9$

(C) Society of General Internal Medicine 2015

\section{BACKGROUND}

The field of primary care remains an unattractive career choice for many medical students. Medical schools have made efforts to increase student exposure in the area of primary care, but the proportion of graduates choosing a primary care career has not increased. Indeed, in the United States, the proportion of graduates choosing a primary care specialty fell from $60.7 \%$ in 1997 to $42.1 \%$ in $2006 .{ }^{1}$ Similarly, between 2005 and 2009 , only $28 \%$ of recent graduates in the United Kingdom planned to go into general practice. ${ }^{2}$ The primary care physician is defined as a specifically trained physician providing first-contact care, taking continuing responsibility for the patient's care, and dealing with all health problems. ${ }^{3},{ }^{4}$ Depending on the country, this includes general practitioners or family physicians, and may also include general pediatricians and general internists.

Research has highlighted that health systems with a strong primary care base are associated with improved health outcomes and a more equitable health distribution among populations. ${ }^{5}$ However, generalists make up only about $30 \%$ of all physicians in OECD (Organisation for Economic Cooperation and Development) countries, ${ }^{6}$ although proportions vary, from $50 \%$ in Australia and Canada, to around $30 \%$ in the United Kingdom, to $12 \%$ in the United States (or approximately one-third if general internists and general pediatricians are counted as well ${ }^{7}$ ). General pediatricians make up a small proportion, ranging from under $2 \%$ (Australia) to almost $10 \%$ (United States). ${ }^{6}$ In order to address the shortage in primary care physicians, medical schools must provide motivation for students to choose a career in primary care.

Specialty choice is complex, influenced by gender, career motivation and life goals, ${ }^{8}$ as well as attitudes about social responsibility. ${ }^{1}$ In a review of the North American literature published through 1993, Bland, Meurer and Maldonado 
identified student- and curriculum-related determinants of primary care specialty choice as described in their paper published in 1995 (Appendix 1). ${ }^{9}$ In a separate paper in 1996, they published a detailed description of the quality of studies on this topic, ${ }^{10}$ concluding that "research in this area predominantly uses the weaker study designs and uses few instruments with known reliability or validity". Based on these findings, the authors suggested strategies to increase the percentage of primary care physicians and to improve research in this field (Appendix 2).

Three other literature reviews have examined primary care specialty choice and have reached similar conclusions (Appendix 1), ${ }^{11-13}$ but were also limited to North American studies. Since Bland and colleagues' comprehensive review, medical schools around the world have developed new initiatives in recognition of the need to increase students' exposure to primary care. Nevertheless, the overall proportion of students choosing a primary care career has not risen. Therefore, we conducted a systematic review of the literature published within the last two decades, with the aim of providing an update of our knowledge about the effectiveness of curricular interventions on primary care specialty choice. We included studies from across the world in order to explore the impact of interventions in a global context.

We sought to answer the following questions:

(1) Which interventions in undergraduate medical education can increase the proportion of students choosing a primary care specialty?

(2) What are the characteristics of successful interventions, and which factors can explain their impact?

(3) What is the state of the quality of the published literature in this area, and how has it evolved since the recommendations published in 1996 ?

\section{METHODS}

We used the PRISMA (Preferred Reporting Items for Systematic Reviews and Meta-Analyses) statement to guide the reporting of our review, ${ }^{14}$ and we registered our protocol in the PROSPERO (international prospective register of systematic reviews) database (record number CRD42014009422). ${ }^{15}$

\section{Definitions}

According to the most frequently used definitions of primary care, we included the specialties of family medicine, general practice, general internal medicine, and general pediatrics.

\section{Search Strategy}

We searched MEDLINE (PubMed), EMBASE, ERIC (EBSCO interface), CINAHL (EBSCO interface), PsycINFO (EBSCO interface), The Cochrane Library, and Dissertations
\& Theses A\&I on February 20, 2015 for papers published since January 1, 1993. We developed a search strategy for each database by combining the key terms "undergraduate medical student", "medical education", "specialty choice", and "primary care", as well as numerous synonyms and subject headings. Our full search strategy for MEDLINE is presented in Appendix 3. Adjusted search strategies for the other databases are available on request. We also scanned the reference lists of included studies for relevant papers.

\section{Eligibility Criteria}

We included original research on interventions focusing on primary care and targeted at medical students, including curricular components, longitudinal interventions, special curriculum tracks, and extracurricular interventions. We only included studies reporting outcomes related to career choice (career intentions during medical school, specialty choice at graduation, and final practice choice). We included studies published in any language, provided they had an abstract in English. We excluded studies of osteopathic medical students, since osteopathy as practiced in the United States does not exist in other countries, where osteopathy is considered an allied health profession. ${ }^{16}$

\section{Study Selection Process}

One reviewer (EP) performed the search, imported the potentially relevant citations into a reference management program (EndNote version X5.0.1; Thomson Reuters, New York, NY, USA) and discarded duplicates. We used a two-stage process to select studies. All titles and abstracts were screened for exclusion criteria by two reviewers (EP and RT, see "Acknowledgements"), and were included for full-text review if chosen by at least one researcher. Two authors (EP and CC) then independently reviewed all available full-text articles for inclusion criteria. Discrepancies were resolved through discussion with another reviewer (DH).

\section{Data Extraction}

Two reviewers (EP and DH) developed a data extraction sheet and pilot-tested it on three articles. EP then extracted data from each article, including study, sample and intervention characteristics, and outcomes relevant for the review. DH independently extracted data from a random sample of six articles to confirm the reliability of the data extraction sheet.

\section{Quality Assessment}

All studies were assessed for quality using two scores (rated from 1 to 5) according to published recommendations, ${ }^{17}$ reflecting the methodological quality of the study and the quality of the information provided in the article. We also graded each article for strength of findings on a scale from 1 to 5 (see Table 1 for details of scores). ${ }^{18}$

Five reviewers (EP, DH, HM, MN, and NJP) pilot-tested the quality scales on six articles. EP then graded all studies, and 
Table 1 Quality Grading of Studies Included in a Systematic Review on Medical Students' Primary Care Career Choices

\begin{tabular}{ll}
\hline Scale & Components of scale \\
\hline $\begin{array}{l}\text { Study quality } \\
1=\text { low } \\
5=\text { high }\end{array}$ & Appropriate research design \\
& Attention to ethical concerns \\
& Adequate recruitment of participants \\
& Adequate data collection methods \\
& Appropriate analyses \\
Quality of information & Statement of study objectives and \\
provided in the published & research questions \\
article & Sufficient information on sampling, \\
$1=$ low & data collection and possible bias \\
$5=$ high & Detailed description of analysis \\
Strength of findings & $1=$ no clear conclusions can be drawn \\
& $2=$ results are weak or ambiguous, but \\
& there appears to be a trend \\
& $3=$ conclusions can probably be \\
drawn from the results \\
$4=$ results are clear and very likely to \\
be true \\
$5=$ results are unequivocal \\
High quality = sum of the three \\
Scores $\geq 10$ and no score $<3$ \\
Overall quality rating & Low quality = sum of the three \\
& scores $<10$ or any score $<3$ \\
\hline
\end{tabular}

two authors (DH, HM) each graded half of the studies to ensure inter-coder reliability. Differences of opinion arose for six studies and were resolved by discussion. We did not exclude any articles from the review based on the quality grading, but we recorded the most common threats to quality.

\section{Analysis and Synthesis of Included Studies}

We could not identify sufficiently large and homogeneous groups of studies to permit quantitative synthesis given the variability in interventions and outcome measures. We therefore synthesized the results narratively, categorizing them into similar types of interventions.

\section{RESULTS}

\section{Study Selection}

Our search strategy yielded 2333 unique citations (Fig. 1), of which 68 articles met our inclusion criteria. We identified four additional articles from reference lists of included papers.

\section{Characteristics of Included Studies}

The 72 articles described 66 different initiatives. ${ }^{19-90}$ A summary of the interventions and their impact is provided in Appendix 4. A more extensive summary of outcomes is available in Appendix 5.

Table 2 provides a summary of the characteristics and methods of the included studies. All articles were written in English, with the exception of one article published in German. ${ }^{39}$ Only $12 \%$ of studies published from 1993 through 1999 took place outside the United States, but this proportion increased to $52 \%$ of studies published from 2000 through 2014. Most studies $(n=65)$ used quantitative methods. Surveys were the most common data collection method. None of

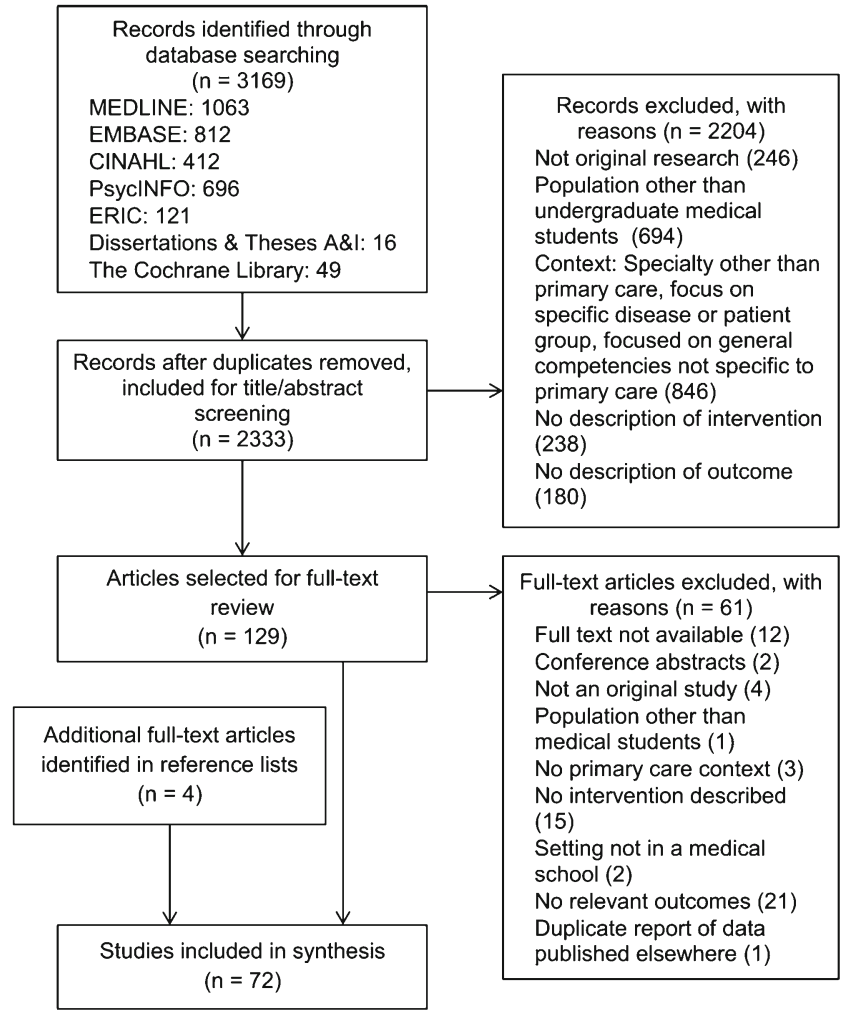

Figure 1 Systematic review flowchart of the literature search and selection process of studies on medical students' choice of a career in primary care, published between January 1, 1993 and February 20, 2015

the papers mentioned a conceptual framework or underlying theory for the study.

\section{Quality Ratings of Included Studies}

Twenty-four studies achieved a high quality score (defined in Table 1). The most common threats to quality were the risk of confounding due to the absence of adjusted statistical analyses, risk of selection bias (through selective admission of students to the intervention), risk of recall bias (in surveys including retrospective items), small sample size, and the lack of a control group (see Appendix 5). The distribution of study quality by regions, intervention type and impact is presented in Table 3.

\section{Impact of Interventions on Primary Care Specialty Choice}

Compulsory Primary Care Clerkships. The duration of the clerkships varied from a few days to 12 weeks. The majority $(n=23)$ took place in ambulatory settings; one clerkship took place in a hospital and four in mixed settings. The most frequently described outcomes were students' career intentions immediately after the clerkship, with 17 studies reporting a positive effect (Table 3). ${ }^{19,23,28,30-33,36-39,41,45}$ One study surveying students after three different clerkships (general 
Table 2 Characteristics of 72 Studies Included in a Systematic Review on Primary Care Specialty Choice

\begin{tabular}{|c|c|}
\hline Characteristic & $N(\%$ of 72$)$ \\
\hline \multicolumn{2}{|l|}{ Location } \\
\hline United States & $41(57)$ \\
\hline Europe & $11(15)$ \\
\hline Australia and New Zealand & $11(15)$ \\
\hline Canada & $4(6)$ \\
\hline Asia & $5(7)$ \\
\hline \multicolumn{2}{|l|}{ Single-/multi-institution } \\
\hline Single medical school & $61(85)$ \\
\hline More than one medical school & $11(15)$ \\
\hline \multicolumn{2}{|l|}{ Type of intervention } \\
\hline Compulsory clerkships & $28(39)$ \\
\hline Longitudinal programs or special curricula & $26(36)$ \\
\hline Electives & $10(14)$ \\
\hline Interest groups & $3(4)$ \\
\hline Student-run free clinic & $3(4)$ \\
\hline Other* & $2(3)$ \\
\hline \multicolumn{2}{|l|}{ Objective of intervention } \\
\hline Promotion of primary care & $35(48)$ \\
\hline Promotion of rural practice & $18(25)$ \\
\hline Promotion of primary care in a rural context & $7(10)$ \\
\hline Promotion of care for underserved populations & $4(6)$ \\
\hline Aim of intervention not specified & $8(11)$ \\
\hline \multicolumn{2}{|l|}{ Timing of the evaluation $\dagger$} \\
\hline Follow-up only & $29(40)$ \\
\hline Pre and post & $12(16)$ \\
\hline Pre, post and follow-up & $10(14)$ \\
\hline Long-term repeated follow-up & $7(10)$ \\
\hline Post and follow-up & $5(7)$ \\
\hline Post & $4(6)$ \\
\hline During & $3(4)$ \\
\hline Pre and follow-up & $2(3)$ \\
\hline \multicolumn{2}{|l|}{ Comparison } \\
\hline Studies using a control group & $30(42)$ \\
\hline Random allocation of students to intervention & $4(6)$ \\
\hline \multicolumn{2}{|l|}{ Data collection method } \\
\hline Survey, unvalidated (or validation not specified) & $39(54)$ \\
\hline National Residency Matching Database & $19(26)$ \\
\hline Other databases & $10(14)$ \\
\hline $\begin{array}{l}\text { Survey, validated (including state-wide } \\
\text { questionnaires) }\end{array}$ & $8(11)$ \\
\hline Physicians' Associations' databases & $7(10)$ \\
\hline Focus groups & $5(7)$ \\
\hline Semi-structured interviews & $4(6)$ \\
\hline Essays & $1(1)$ \\
\hline Studies using more than one data collection method & $15(21)$ \\
\hline Methods of quantitative data analysis & $\mathrm{N}(\%$ of 65$)$ \\
\hline Inferential statistics, unadjusted & $31(48)$ \\
\hline Descriptive statistics only & $21(32)$ \\
\hline $\begin{array}{l}\text { Inferential statistics, adjusted for more than } \\
3 \text { independent variables }\end{array}$ & $7(11)$ \\
\hline $\begin{array}{l}\text { Inferential statistics, adjusted for } 1 \text { to } 3 \\
\text { independent variables }\end{array}$ & $6(9)$ \\
\hline
\end{tabular}

*Includes an integrated residency program and an intercalated research degree.

HIndicates when data were collected: follow-up (at a point beyond the immediate completion of the intervention); pre (before or at the beginning of the intervention); post (immediately following the end of the intervention); long-term repeated follow-up (longitudinal database follow-up of students and/or graduates over several years); during (during the course of the intervention)

practice, internal medicine and surgery) suggested that the positive effect of clerkships may not be specific to primary care. ${ }^{23}$ The impact on students' career choices at graduation varied across studies. Most interventions with a positive impact were clerkships in family medicine $e^{22,26,30,31,39}$ or general practice, ${ }^{19,32,34}$ as opposed to other types of clerkships (such as community placements). Only one study included a longterm outcome -8 years after a general practice placement, physicians' attitudes were still positively influenced - but this was unrelated to final career choices. ${ }^{25}$ Outcomes did not differ according to the timing of the clerkship in the curriculum (preclinical versus clinical years, final versus penultimate year).

Some studies suggested that the impact of clerkships depended on their intrinsic qualities, such as student perception of educational value, ${ }^{22}$ student satisfaction with attending physicians and the quality of teaching, ${ }^{38}$ or the specialty of teaching physicians. ${ }^{28}$ In a small qualitative study, graduates stated that contact with family physician role models and the opportunity to see the diverse nature of work in family practice had been important experiences influencing their specialty choice. $^{44}$

Longitudinal Programs. Of 21 different programs (described in 26 papers), 15 were primary care courses added to the conventional curriculum. ${ }^{49-53,55-59,63-66,68-72}$ The remaining six programs were special curricula or medical schools focusing on primary care and/or rural health. ${ }^{47,48,54,60-62}$, Contrary to the studies on clerkships, the most frequently studied outcomes of longitudinal programs were career choices after graduation $(n=15)$. Of these, seven programs had a higher proportion of graduates choosing primary care compared to traditional graduates.

All programs but one ${ }^{67}$ included clinical placements. With one exception, ${ }^{72}$ all high quality studies were from the United States, and most of them had a positive impact (Table 3 ). Components of these programs included longitudinal preclinical preceptorships ${ }^{47,49,50}$ family medicine faculty advisors, ${ }^{52}$ clinical rotations at rural or regional sites, ${ }^{47,48,50,52,54}$ workshops or seminars on primary care, ${ }^{48-50}$ and community-based projects. ${ }^{50}$ Most of them also recruited students according to predictors of career choice previously described in the literature, including the students' childhood community and interest in primary care. ${ }^{47,50,52,54}$

Most programs $(n=19)$ were offered to students on a voluntary basis, or used specific recruitment and admission procedures to select students interested in primary care, thus introducing a potential selection bias. The majority of studies comparing career choices of program participants to nonparticipants found that participants were more likely to choose primary care specialties. However, the effect of the selection process could not be separated from the impact of the program itself. Only two studies reduced selection bias by randomly choosing program participants among interested students. One found a significant association between program participation and residency choice, ${ }^{49}$ whereas the other suggested that the effect of preexisting interest was a stronger predictor of specialty choice. ${ }^{56}$ One study found an additive effect of a preclinical curriculum and a clinical longitudinal preceptorship on students' choice of primary care specialty. ${ }^{47}$

Two qualitative studies explored student attitudes in community-based curricula. In the first, students commented on persistent negative preconceptions about general practice, 
Table 3 Distribution of 72 Studies Included in a Systematic Review According to Region, Study Quality, Intervention Type, and Impact on Primary Care Career Choice

\begin{tabular}{|c|c|c|c|c|c|c|c|}
\hline \multirow[t]{2}{*}{ Intervention type } & \multirow[t]{2}{*}{ Impact* } & \multicolumn{2}{|l|}{ United States } & \multicolumn{2}{|l|}{ Europe } & \multicolumn{2}{|l|}{ Other§ } \\
\hline & & $\begin{array}{l}\text { High quality } \\
\text { studies } \dagger\end{array}$ & $\begin{array}{l}\text { Low quality } \\
\text { studies }\end{array}$ & $\begin{array}{l}\text { High-quality } \\
\text { studies }\end{array}$ & $\begin{array}{l}\text { Low-quality } \\
\text { studies }\end{array}$ & $\begin{array}{l}\text { High-quality } \\
\text { studies }\end{array}$ & $\begin{array}{l}\text { Low-quality } \\
\text { studies }\end{array}$ \\
\hline \multirow[t]{2}{*}{ Compulsory clerkships } & Positive & $\bullet \bullet \bullet$ & ००० & $\bullet$ & 0000 & & 0000000 \\
\hline & $\begin{array}{l}\text { None, negative } \\
\text { or unknown }\end{array}$ & $\boldsymbol{\Delta} \boldsymbol{\Delta}$ & $\Delta \Delta \Delta$ & $\boldsymbol{\Delta}$ & $\Delta$ & $\boldsymbol{\Delta} \boldsymbol{\Delta} \boldsymbol{\Delta}$ & \\
\hline \multirow[t]{2}{*}{ Longitudinal programs } & Positive & $\bullet \bullet \bullet \bullet \bullet \bullet \bullet \bullet \bullet$ & 000000 & $\bullet$ & & & ० \\
\hline & $\begin{array}{l}\text { None, negative } \\
\text { or unknown }\end{array}$ & $\boldsymbol{\Delta}$ & $\Delta \Delta$ & & & & $\Delta \Delta \Delta \Delta \Delta \Delta$ \\
\hline \multirow[t]{2}{*}{ Electives } & Positive & $\bullet$ & 0000 & & ० & & ० \\
\hline & $\begin{array}{l}\text { None, negative } \\
\text { or unknown }\end{array}$ & & $\Delta \Delta$ & & $\Delta$ & & \\
\hline \multirow[t]{2}{*}{ Other interventions } & Positive & & ००० & $\bullet$ & & & ० \\
\hline & $\begin{array}{c}\text { None, negative } \\
\text { or unknown }\end{array}$ & & $\Delta \Delta$ & & & & $\Delta$ \\
\hline
\end{tabular}

*Impact of the intervention on the relevant outcome (see Appendix 4, Outcome and Impact). For studies including more than one outcome, the most relevant was taken (order of relevancy: final career choice>career choice at graduation>career intention)

Circles symbolize studies with a positive impact; triangles symbolize studies with no impact, unknown impact or negative impact on the most relevant outcome. $\bullet / \mathbf{\Delta}=$ high-quality studies (as defined in Table 1), $\mathrm{o} / \Delta=$ low-quality studies

Includes studies from The Netherlands, Spain, United Kingdom, and Germany

§Includes studies from Australia, New Zealand, Canada, Japan, Pakistan, and Hong Kong

but stated that good-quality attachments to general practitioners were able to reverse these negative attitudes. ${ }^{72}$ The quality of clerkships was rated highly when they offered opportunities to see a diverse mix of patients, to have interactive experiences, and to be in a practice team that made them feel welcome. The other study took place in the context of a state-mandated initiative. ${ }^{71}$ Students felt that primary care was imposed on the school by outside agencies, and that medical school faculty were censored and not allowed to promote subspecialty careers. They also felt unable to obtain unbiased career counseling.

Electives. The duration of electives varied from 3 days to 8 weeks, and most $(n=9)$ included clinical primary care experiences. Five studies compared participants to nonparticipants. Of these, three studies found participants more likely to choose a primary care specialty than nonparticipants. ${ }^{73,74,81}$ Only one study included a measure of pre-existing interest in primary care, for which the authors found no difference between the two groups. ${ }^{76}$ Five studies used before-and-after questionnaires to measure the impact of the elective, without using control groups. Three of these studies found that the elective had a positive influence on students' attitudes towards a career in primary care. ${ }^{75,80,82}$

Interest Groups. Three papers described student-led interest groups, offering a range of activities for students interested in family medicine or primary care. One study found that students participating in an interprofessional primary care interest group were more likely than non-participants to choose a primary care residency. ${ }^{83}$ The other two studies suggested a positive influence of a family medicine interest group on student interest in family medicine, but could not ascertain that the group actively influenced career choice. ${ }^{84,85}$
Student-Run Free Clinics. Participation in a student-run free clinic was found to increase students' interest in primary care, ${ }^{87}$ but did not influence specialty choice. ${ }^{86,88}$

Integrated Residency Program. One paper described an integrated residency in general internal medicine, combining the requirements of the last year of medical school and the first year of residency. ${ }^{89}$ Although a large proportion of participants chose to pursue general internal medicine, the study was too small to allow firm conclusions.

Participation in Primary Care Research. Jones and colleagues interviewed students undertaking a year-long intercalated research degree in primary care. ${ }^{90}$ The course did not change students' career intentions, as most of them were already committed to general practice, but students perceived that the course extended their skills and reinforced their career choice.

\section{DISCUSSION}

Twenty years after the last comprehensive literature review, as reported by Bland and colleagues, our main conclusions are similar to those in their publication: longitudinal programs are the only strategy that significantly increases the proportion of medical school graduates choosing a primary care specialty, as illustrated by several studies in our review that reported on long-standing longitudinal programs. Most of these programs have been focused within a rural context in the United States and Australia, where primary care physician shortages are an important issue. We found no reports on similar interventions in Europe or other parts of the world (with the exception of one 
medical school for rural practice in a Japanese $\operatorname{study}^{21}$ ). Still, primary care physician shortages have developed in several European countries, ${ }^{91}$ and remain unresolved in emerging countries such as China, India and South Africa. ${ }^{6}$ Medical schools around the world, therefore, could be inspired by some of these enduring American and Australian programs.

We found conflicting evidence on the impact of compulsory clerkships. They often positively influenced students' attitudes about primary care, but without affecting career choice. Interestingly, most clerkships with a positive impact were in family medicine or general practice, as opposed to those, for example, in general internal medicine or rural practice. This resonates with Bland and colleagues' finding that family practice is the only primary care discipline in which a clerkship is correlated with specialty choice. The variety of clerkships in our review explains the fact that our findings are less clear-cut, although they suggest that clerkships can help students in clarifying the role and content of primary care practice, and may act to counterbalance negative preconceptions towards primary care. Electives may further strengthen the interests of individual students and help clarify future career pathways. ${ }^{92}$

\section{The State of Quality of the Studies in Our Review}

We found that the quality of the specialty choice literature had not improved during the last two decades. Our findings reaffirm some of the major threats to quality that had previously been noted, such as the frequent use of instruments without known reliability or validity and the use of study designs at greater risk of bias. ${ }^{10}$ Observational studies are rarely useful for evaluating initiatives, as the impact of other influences is difficult to estimate. ${ }^{93}$ Conceptual frameworks are helpful for formulating research questions and discussing generalizability,${ }^{94}$ yet none of these were mentioned in any of the studies in our review. Only a minority of studies included several independent variables in their analyses, despite the fact that many influencing factors have been described in the literature, such as gender, background and parental income. The recommendations published in 1996 are therefore still relevant for medical education researchers today. Based on our findings, we suggest several additions to these recommendations (Table 4).

\section{Strengths and Weaknesses of the Review}

Our review adds a global perspective to the previous specialty choice reviews. Although a majority of studies are still produced in the United States, international publications have increased since 2000. These studies detail initiatives in diverse contexts but also introduce greater heterogeneity. The clerkships, for example, are varied in their duration, setting, and content. This limits their comparability, and may explain some of the contradictory findings across studies. Another explanation is the insufficient use of optimal study designs, threatening the internal and external validity of many of the included studies. The global perspective adds further difficulties, including the various definitions of primary care and variations in the duration of medical education. These issues highlight the difficulties that medical schools may encounter in implementing evidence-based interventions within their own specific context.

We preferred a general score over a strict point-based scoring system for evaluating the quality of the studies. Although this score could be viewed as more subjective, we limited this risk by pilot-testing the score within the review group and by having all articles graded by at least two authors, achieving good reliability. Contrary to previous reviews, we did not exclude studies based on their quality score, but preferred to critically present the full scope of the literature.

Our review has further limitations. It was limited to the pregraduate medical curriculum, and therefore we cannot draw

Table 4 Recommendations for Medical Education Researchers for Improving the Quality of Research in the Area of Primary Care Specialty Choice, Based on the Present Review and on Previous Recommendations

Recommendations of Meurer, Bland and Maldonado (see Appendix 2 for details)

1. Develop and/or identify reliable and valid instruments (...)

2. Use consistent definitions of primary care and of specialty choice

3. Encourage researchers to use a model or theory $(\ldots)$. Researchers should include all the many variables they believe influence specialty choice (...).

6. Conduct further research on the Bland-Meurer model and alternative causal models.

4. Use experimental designs whenever possible.

5. (...) use a longitudinal rather than a retrospective approach.
Specific recommendations based on findings of the present review

Whenever possible, use instruments with known validity.

Reflect on possibilities to measure outcome variables related to career choice:

- Objective vs. subjective measurements,

- Career intentions vs. career choice at graduation vs. final career choice.

Be aware of variability in definitions of primary care specialties across

countries, and specify the definition used in the context of the study.

Using a model or framework that includes all known variables will help formulate research questions, justify the rationale for the study, and discuss generalizability

Assess these variables with valid instruments.

Use appropriate statistical methods to adjust for as many of these variables as possible.

Consider using stronger study designs:

- Use appropriate control groups, and randomization if possible.

- Favor longitudinal approaches.

- Consider building program-specific databases to evaluate long-term outcomes.

- Avoid uncontrolled before-and-after surveys, as observed changes are often difficult to attribute to the intervention because of confounding by other influences. 
conclusions regarding the impact of political and other contextual influences. Although we searched several databases, including an educational resource, we did not search further for grey literature, and our search was limited to published papers. We excluded ten papers because we could not retrieve the full-text version. However, we read their abstracts and could not identify findings that would have added evidence.

\section{Implications of the Review}

Our findings suggest that longitudinal programs are the most effective for promoting primary care, yet clerkships remain the most frequently described intervention. Building on Bland and colleagues' recommendations, and based on our findings, we provide updated recommendations for medical educators wishing to make changes to strengthen primary care in their curriculum (Table 5). The impact of any program depends on its quality, which is closely related to preceptors' teaching behaviors. Good precepting includes actively involving students in patient assessment, giving feedback, and spending time teaching. ${ }^{95}$ We also encourage medical schools to discuss selection strategies and career support, which must remain unbiased despite our will to promote primary care. ${ }^{96}$ Although our review is limited to pre-graduate medical education, the broader context of cultural aspects, political influences and financial incentives must be considered. Educational efforts should not be expected to increase the number of primary care physicians if primary care practice is not encouraged within the medical system, as suggested by some of the studies in our review. ${ }^{21,35,41,43,46}$

Table 5 Recommendations for Curricular Interventions to Increase the Proportion of Medical Students Choosing Primary Care, Based on the Findings of the Present Literature Review and on Previous Recommendations Published in 1995

\begin{tabular}{|c|c|c|}
\hline $\begin{array}{l}\text { Recommendations by Bland, Meurer and } \\
\text { Maldonado (see Appendix } 2 \text { for details) }\end{array}$ & $\begin{array}{l}\text { Recommendations based on the findings } \\
\text { of the present literature review }\end{array}$ & Examples from the present review \\
\hline $\begin{array}{l}\text { 7. Establish required longitudinal primary } \\
\text { care experiences. } \\
\text { 9. Establish a course on the health care needs } \\
\text { of society and the physician's role. }\end{array}$ & $\begin{array}{l}\text { Establish longitudinal primary care } \\
\text { programs, combining diverse learning } \\
\text { experiences. }\end{array}$ & $\begin{array}{l}\text { Successful programs include the following } \\
\text { components: } \\
\text { - Preclinical preceptorship: repeated sessions } \\
\text { in a primary care physician's office } \\
\text { - Lectures or seminars on population-based health } \\
\text { - Clinical clerkships in family medicine or general } \\
\text { practice } \\
\text { - Community-based research or public health project } \\
\text { work } \\
\text { - Electives for interested students }\end{array}$ \\
\hline $\begin{array}{l}\text { 5. Use recruitment and selection processes that } \\
\text { are most likely to attract students who will } \\
\text { choose primary care careers. } \\
\text { 3. Change admission policies to favour } \\
\text { students who are interested in primary care }\end{array}$ & $\begin{array}{l}\text { Discuss and reflect on selection strategies } \\
\text { and admission criteria. } \\
\text { Consider including evidenced-based } \\
\text { personal criteria in addition to academic } \\
\text { performance. }\end{array}$ & $\begin{array}{l}\text { Personal characteristics known to increase the likelihood of } \\
\text { students choosing primary care careers include: } \\
\text { - Pre-existing interest in primary care and community- } \\
\text { based health care } \\
\text { - Type of community where students have been raised }\end{array}$ \\
\hline
\end{tabular}
and to give weight to student characteristics likely to predict future primary care career choices.

4. Change the composition of admission commit tees $(. .$.

8. Establish required third-year family practice clerkships.

Establish high-quality clinical clerkships in general practice or family practice.

Whenever possible, include the clerkship in a longitudinal program (see above).

Be aware of the possible negative impact of low-quality clerkships.

Offer unbiased career counseling and support, helping students make their own choice.

Be aware that too much political support for primary care may have negative effects if students feel that primary care is imposed on them.

Consider the broader context before implementing major curricular changes, including the political and cultural context, postgraduate education and financial incentives.

Use good-quality research to evaluate programs, and share the outcomes with others.
Elements defining high-quality clerkships include:

- Active, hands-on experiences (as opposed to "sitting in the corner watching")

- A good relationship with the preceptor and the practice team ("feeling welcome")

- The opportunity to see a variety of patients and to be able to follow them over time

- Structured teaching and good-quality feedback from preceptors

Primary care career support can be offered through formal or informal means:

- Primary care faculty advisors or mentors

- Family medicine or primary care student interest groups

Successful primary care programs and special medical schools include a strong institutional mission for promoting primary care.

See recommendations for research in Table 4 . 


\section{Conclusions and Recommendations for Future Research}

Our findings suggest a need to develop multifaceted strategies organized in coherent longitudinal programs in order to increase the proportion of students who wish to become primary care physicians. We confirm the main findings of a review published two decades ago, whilst adding a global perspective. We also note that the quality of the research has not improved since the last comprehensive review. However, some literature demonstrates that it is possible to conduct controlled experimental studies to evaluate initiatives. It is essential to conduct high-quality research to evaluate new programs and to share the outcomes so that others can replicate successful initiatives. We encourage medical educators to be inspired by Bland, Meurer and Maldonado's recommendations, which remain highly relevant two decades after their publication, and which we have updated. Last but not least, we must not forget that even a well-designed primary care curriculum will only be successful if the broader context is favorable to primary care.

ACKNOWLEDGMENTS: Contributors: This project was developed as part of the activities of SAFMed (Swiss Academy of Family Medicine). The authors thank Dr. Romain Teoli, research assistant, for his collaboration in the abstract selection process.

Funders: Eva Pfarrwaller and Christopher Chung were funded by the "Masterplan for family medicine", as part of the activities of SAFMed, a program for the academic development of family medicine supported by the Swiss University Conference and the Swiss State Secretariat for Education, Research and Innovation.

Prior Presentations: Select results were presented at the 2014 Swiss Family Docs Conference (August 2014, Zurich, Switzerland).

Conflict of Interest: The authors declare that they do not have any conflicts of interest.

Corresponding Author: Eva Pfarrwaller, M.D.; Primary Care Unit, Faculty of Medicine, Centre Médical UniversitaireUniversity of Geneva, Av. de Champel 9 1211, Genève 4, Switzerland (e-mail: eva.pfarrwaller@unige.ch).

\section{REFERENCES}

1. Jeffe DB, Whelan AJ, Andriole DA. Primary care specialty choices of United States medical graduates, 1997-2006. Acad Med. 2010;85(6):94758.

2. Svirko E, Goldacre MJ, Lambert T. Career choices of the United Kingdom medical graduates of 2005, 2008 and 2009: questionnaire surveys. Med Teach. 2013;35(5):365-75.

3. American Academy of Family Physicians (AAFP). Policies: Primary Care. Available at: http://www.aafp.org/about/policies/all/primary-care.html. Accessed 28 March 2015.

4. Evans P. editor. The European Definition of General Practice/Family Medicine, Short Version. European Academy of Teachers in General Practice; 2005. Available from: http://woncaeurope.org/sites/default/ files/documents/Definition\%20EURACTshort\%20version.pdf. Accessed 28 March 2015.

5. Starfield B, Shi L, Macinko J. Contribution of primary care to health systems and health. Milbank Q. 2005;83(3):457-502.

6. OECD Directorate for Employment, Labour and Social Affaires. OECD Health Statistics 2014 Online Database. Available at: http://www.oecd. org/health/healthdata. Accessed 28 March 2015.
7. Agency for Healthcare Research and Quality. Fact Sheets: The Number of Practicing Primary Care Physicians in the United States. Available at: http://www.ahrq.gov/research/findings/factsheets/primary/pcwork1/ index.html. Accessed 28 March 2015.

8. Buddeberg-Fischer B, Stamm M, Buddeberg C, et al. The impact of gender and parenthood on physicians' careers-professional and personal situation seven years after graduation. BMC Health Serv Res. 2010;10:40.

9. Bland CJ, Meurer LN, Maldonado G. Determinants of primary care specialty choice: a non-statistical meta-analysis of the literature. Acad Med. 1995;70(7):620-41.

10. Meurer LN, Bland CJ, Maldonado G. The state of the literature on primary care specialty choice: where do we go from here? Acad Med. 1996;71(1):68-77.

11. Meurer LN. Influence of medical school curriculum on primary care specialty choice: analysis and synthesis of the literature. Acad Med. 1995;70(5):388-97.

12. Campos-Outcalt D, Senf J, Watkins AJ, Bastacky S. The effects of medical school curricula, faculty role models, and biomedical research support on choice of generalist physician careers: a review and quality assessment of the literature. Acad Med. 1995;70(7):611-9.

13. Senf JH, Campos-Outcalt D, Kutob R. Factors related to the choice of family medicine: a reassessment and literature review. J Am Board Fam Pract. 2003; 16(6):502-12.

14. Moher D, Liberati A, Tetzlaff J, Altman DG, for the PRISMA Group. Preferred Reporting Items for Systematic Reviews and Meta-Analyses: the PRISMA Statement. BMJ. 2009;339:b2535. doi:10.1136/bmj.b2535.

15. Booth A, Clarke M, Dooley G, et al. The Nuts and Bolts of PROSPERO: an International Prospective Register of Systematic Reviews. Syst Rev. 2012;1:2. doi:10.1186/2046-4053-1-2.

16. Osteopathic International Alliance. Defining the Profession. Available at: http://wp.oialliance.org/about-us/osteopathic-medicine-and-osteopathy. Accessed 28 March 2015.

17. Huwiler-Muntener K, Juni P, Junker C, Egger M. Quality of reporting of randomized trials as a measure of methodologic quality. JAMA. 2002;287(21):2801-4.

18. Hammick M, Dornan T, Steinert Y. Conducting a best evidence systematic review. Part 1: from idea to data coding. BEME Guide No. 13. Med Teach. 2010;32(1):3-15.

19. Maiorova T, Stevens F, van der Zee J, Boode B, Scherpbier A. Shortage in general practice despite the feminisation of the medical workforce: a seeming paradox? A cohort study. BMC Health Serv Res. 2008;8:262.

20. Gazewood JD, Owen J, Rollins LK. Effect of generalist preceptor specialty in a third-year clerkship on career choice. Fam Med. 2002;34(9):673-7.

21. Takayashiki A, Inoue $\mathbf{K}$, Okayama $\mathbf{M}$, et al. Primary care education in Japan: is it enough to increase student interest in a career in primary care? Educ Prim Care. 2007; 18(2):156-64.

22. Levy BT, Hartz A, Merchant ML, Schroeder BT. Quality of a family medicine preceptorship is significantly associated with matching into family practice. Fam Med. 2001;33(9):683-90.

23. Maiorova T, Stevens F, Scherpbier A, van der Zee J. The impact of clerkships on students' specialty preferences: what do undergraduates learn for their profession? Med Educ. 2008;42(6):554-62.

24. Woloschuk W, Tarrant M. Does a rural educational experience influence students' likelihood of rural practice? Impact of student background and gender. Med Educ. 2002;36(3):241-7.

25. Williamson MI, Wilson R, McKechnie R, Ross J. Does the positive influence of an undergraduate rural placement persist into postgraduate years? Rural Remote Health. 2012;12:2011.

26. Campos-Outcalt D, Senf J. A longitudinal, national study of the effect of implementing a required third-year family practice clerkship or a department of family medicine on the selection of family medicine by medical students. Acad Med. 1999;74(9):1016-20.

27. Packer CD, Carnell RC, Tomcho PM, Scott JG. Development of a fourday service-learning rotation for third-year medical students. Teach Learn Med. 2010;22(3):224-8.

28. Henderson MC, Hunt DK, Williams JW Jr. General internists influence students to choose primary care careers: the power of role modeling. Am J Med. 1996;101(6):648-53.

29. Hunt DK, Badgett RG, Woodling AE, Pugh JA. Medical student career choice: do physical diagnosis preceptors influence decisions? Am J Med Sci. 1995;310(1):19-23.

30. Rabadan FE, Hidalgo JL. Changes in the knowledge of and attitudes toward family medicine after completing a primary care course. Fam Med. 2010;42(1):35-40.

31. Geske JA, Hartman T, Goodman B, Paulman P. Influence of a rural family medicine rotation on residency selection: MS3 versus MS4. Fam Med. 2011;43(8):556-9. 
32. Howe A, Ives G. Does community-based experience alter career preference? New evidence from a prospective longitudinal cohort study of undergraduate medical students. Med Educ. 2001;35(4):391-7.

33. Williamson M, Gormley A, Bills J, Farry P. The new rural health curriculum at Dunedin School of Medicine: how has it influenced the attitudes of medical students to a career in rural general practice? $\mathrm{N} Z \mathrm{Med}$ J. 2003;116(1179):U537.

34. Hogg R, Spriggs B, Cook V. Do medical students want a career in general practice? A rich mix of influences! Educ Prim Care. 2008;19(1):54-64.

35. Tani $\mathbf{K}$, Yamaguchi $\mathbf{H}$, Tada $\mathbf{S}$, et al. Community-based clinical education increases motivation of medical students to medicine of remote area -comparison between lecture and practice. J Med Investig. 2014;61(1-2):156-61.

36. Corbett EC Jr, Owen JA, Hayden GF. Effect of a second-year primary care preceptorship on medical students' career plans. South Med J. 2002;95(7):691-4.

37. Morrison JM, Murray TS. Career preferences of medical students: influence of a new four-week attachment in general practice. $\mathrm{Br} \mathrm{J}$ Gen Pract. 1996;46(413):721-5.

38. Arora V, Wetterneck TB, Schnipper JL, et al. Effect of the inpatient general medicine rotation on student pursuit of a generalist career. J Gen Intern Med. 2006;21(5):471-5.

39. Dunker-Schmidt C, Breetholt A, Gesenhues S. 15 Years of practical training for the medical students in periods of 2 weeks in general practice: experiences at the University of Duisburg-Essen [in German]. ZFA (Stuttgart). 2009;85(4):171-5.

40. Senf $\mathbf{J H}$, Campos-Outcalt $\mathbf{D}$. The effect of a required third-year family medicine clerkship on medical students' attitudes: value indoctrination and value clarification. Acad Med. 1995;70(2):142-8.

41. Iqbal SP. Family medicine in undergraduate medical curriculum: a cost effective approach to health care in Pakistan. J Ayub Med Coll Abbottabad. 2010;22(4):207-9.

42. Davidson RA, Harris Jo, Schwartz MD. A simple ambulatory-care experience and students' residency choices and attitudes toward general internal medicine. Acad Med. 1993;68(4):311-2.

43. Tai-pong L. Medical graduates' attitudes towards their undergraduate general practice teaching in Hong Kong. Med Teach. 1997;19(1):62-4.

44. Jordan J, Brown JB, Russell G. Choosing family medicine. What influences medical students? Can Fam Physician. 2003;49:1131-7.

45. Parker JE, Hudson B, Wilkinson TJ. Influences on final year medical students' attitudes to general practice as a career. J Prim Health Care. 2014;6(1):56-63.

46. Dixon AS, Lam CL, Lam TP. Does a brief clerkship change Hong Kong medical students' ideas about general practice? Med Educ. 2000;34(5):339-47.

47. Zink T, Center B, Finstad D, et al. Efforts to graduate more primary care physicians and physicians who will practice in rural areas: examining outcomes from the university of Minnesota-Duluth and the rural physician associate program. Acad Med. 2010;85(4):599-604.

48. Phillips TJ, Rosenblatt RA, Schaad DC, Cullen TJ. The long-term effect of an innovative family physician curricular pathway on the specialty and location of graduates of the University of Washington. Acad Med. 1999;74(3):285-8.

49. Grayson MS, Klein M, Franke KB. Impact of a first-year primary care experience on residency choice. J Gen Intern Med. 2001;16(12):860-3.

50. Haq C, Stearns M, Brill J, et al. Training in Urban Medicine and Public Health: TRIUMPH. Acad Med. 2013;88(3):352-63.

51. Rabinowitz HK, Diamond JJ, Markham FW, Hazelwood CE. A program to increase the number of family physicians in rural and underserved areas: impact after 22 years. JAMA. 1999;281(3):255-60.

52. Rabinowitz HK, Diamond JJ, Markham FW, Santana AJ. Increasing the supply of rural family physicians: recent outcomes from Jefferson Medical College's Physician Shortage Area Program (PSAP). Acad Med. 2011;86(2):264-9.

53. Rabinowitz HK, Petterson S, Boulger JG, et al. Medical school rural programs: a comparison with international medical graduates in address ing state-level rural family physician and primary care supply. Acad Med. 2012;87(4):488-92.

54. Crump WJ, Fricker RS, Ziegler C, Wiegman DL, Rowland ML. Rura track training based at a small regional campus: equivalency of training. residency choice, and practice location of graduates. Acad Med. 2013;88(8):1122-8.

55. Halaas GW, Zink T, Finstad D, Bolin K, Center B. Recruitment and retention of rural physicians: outcomes from the rural physician associate program of Minnesota. J Rural Health. 2008;24(4):345-52.

56. Herold AH, Woodard LJ, Pamies RJ, Roetzheim RG, van Durme DJ, Micceri T. Influence of longitudinal primary care training on medical students' specialty choices. Acad Med : J Assoc Am Med Coll. 1993;68(4):281-4.

57. Stearns J, Glasser M, Miller B, Flach D, Cowen J. A longitudina ambulatory care clerkship: graduates' reports on the effect of specialty choice and preparation for residency. Acad Med. 1993;68(suppl 10):S3739.

58. Florence JA, Goodrow B, Wachs J, Grover S, Olive KE. Rural health professions education at East Tennessee State University: survey of graduates from the first decade of the community partnership program. J Rural Health. 2007;23(1):77-83.

59. Stagg P, Greenhill J, Worley PS. A new model to understand the career choice and practice location decisions of medical graduates. Rural Remote Health. 2009;9(4): 1245

60. Mennin SP, Kalishman S, Friedman M, Pathak D, Snyder J. A survey of graduates in practice from the University of New Mexico's conventional and community-oriented problem-based tracks. Acad Med. 1996;71(10):107989.

61. Sen Gupta T, Murray R, Hays R, Woolley T. James Cook University MBBS graduate intentions and intern destinations: a comparative study with other Queensland and Australian medical schools. Rural Remote Health. 2013;13(2):1-10.

62. Veitch C, Underhill A, Hays RB. The career aspirations and location intentions of James Cook University's first cohort of medical students: a longitudinal study at course entry and graduation. Rural Remote Health. 2006;6(1):537.

63. Eley D, Baker P, Chater B. The Rural Clinical School Tracking Project: more IS better-confirming factors that influence early career entry into the rural medical workforce. Med Teach. 2009;31(10):e454-459.

64. Glasser M, Hunsaker M, Sweet K, MacDowell M, Meurer M. A comprehensive medical education program response to rural primary care needs. Acad Med. 2008;83(10):952-61.

65. Walker JH, DeWitt DE, Pallant JF, Cunningham CE. Rural origin plus a rural clinical school placement is a significant predictor of medical students' intentions to practice rurally: a multi-university study. Rural Remote Health. 2012;12(1): 1-9.

66. Wilkinson JE, Hoffman M, Pierce E, Wiecha J. FaMeS: an innovative pipeline program to foster student interest in family medicine. Fam Med. 2010;42(1):28-34

67. Roman SA Jr, McGanney ML. The Sophie Davis School of Biomedical Education: the first 20 years of a unique BS-MD program. Acad Med. 1994;69(3):224-30.

68. Bland CJ, Starnaman S, Harris D, Henry R, Hembroff L. 'No fear' curricular change: monitoring curricular change in the W. K. Kellogg Foundation's national initiative on community partnerships and health professions education. Acad Med. 2000;75(6):623-33.

69. Young L, Kent L, Walters L. The John Flynn Placement Program: evidence for repeated rural exposure for medical students. Aust J Rural Health. 2011;19(3): 147-53.

70. Eley DS, Synnott R, Baker PG, Chater AB. A decade of Australian Rural Clinical School graduates-where are they and why? Rural Remote Health. 2012; 12:1937.

71. Kuzel AJ, Moore SS. Choosing a specialty during a generalist initiative: a focus group study. Fam Med. 1999;31(9):641-6.

72. Firth A, Wass V. Medical students' perceptions of primary care: the influence of tutors, peers and the curriculum. Educ Prim Care. 2007; 18(3):364-72.

73. Kane KY, Quinn KJ, Stevermer JJ, et al. Summer in the country: changes in medical students' perceptions following an innovative rural community experience. Acad Med. 2013;88(8):1157-63.

74. Nieman LZ, Foxhall LE, Chuang AZ, Cheng L, Prager TC. Evaluating the Texas statewide family practice preceptorship program, 1992-2000. Acad Med. 2004;79(1):62-8.

75. Deutsch T, Honigschmid P, Frese T, Sandholzer H. Early communitybased family practice elective positively influences medical students' career considerations - a Pre-post-comparison. BMC Fam Pract. 2013;14:24.

76. Dobie SA, Carline JD, Laskowski MB. An early preceptorship and medical students' beliefs, values, and career choices. Adv Health Sci Educ Theory Pract. 1996;2(1):35-47.

77. Davidson RA. Community-based education and problem-solving: the community health scholars program at the University of Florida. Teach Learn Med. 2002;14(3):178-81.

78. Seim HC. Rural family practice program for first-year students. Acad Med. 1997;72(9):735-6.

79. Farmer J, Iversen L, Bond C, Duthie I. Medical students' orientation towards rural general practice: results from an exploratory study of a Scottish cohort. Educ Prim Care. 2003;14(4):463-7. 
80. Talbot J, Ward A. Alternative Curricular Options in Rural Networks (ACORNS): impact of early rural clinical exposure in the University of West Australia medical course. Aust J Rural Health. 2000;8(1):17-21.

81. Bruno DM, Imperato PJ, Szarek M. The correlation between global health experiences in low-income countries on choice of primary care residencies for graduates of an urban US medical school. J Urban Health. 2014;91(2):394-402.

82. Crosson J, Heaton CJ, Boyd L. The summer assistantship in patient education: a preclinical preceptorship. Fam Med. 2003;35(1):15-7.

83. Norris TE, House P, Schaad D, Mas J, Kelday JM. Student providers aspiring to rural and underserved experiences at the University of Washington: promoting team practice among the health care professions. Acad Med. 2003;78(12):1211-6.

84. McKee ND, McKague MA, Ramsden VR, Poole RE. Cultivating interest in family medicine: family medicine interest group reaches undergraduate medical students. Can Fam Physician. 2007;53(4):661-5.

85. Kerr JR, Seaton MB, Zimcik H, McCabe J, Feldman K. The impact of interest: how do family medicine interest groups influence medical students? Can Fam Physician. 2008;54:78-9.

86. Tong ST, Phillips RL, Berman R. Is exposure to a student-run clinic associated with future primary care practice? Fam Med. 2012;44(8):579-81.

87. Smith SD, Yoon R, Johnson ML, Natarajan L, Beck E. The effect of involvement in a student-run free clinic project on attitudes toward the underserved and interest in primary care. J Health Care Poor Underserved. 2014;25(2):877-89.

88. Vaikunth SS, Cesari WA, Norwood KV, et al. Academic achievement and primary care specialty selection of volunteers at a student-run free clinic. Teach Learn Med. 2014;26(2):129-34.
89. Chang LL, Grayson MS, Patrick PA, Sivak SL. Incorporating the fourth year of medical school into an internal medicine residency: effect of an accelerated program on performance outcomes and career choice. Teach Learn Med. 2004; 16(4):361-4.

90. Jones M, Singh S, Lloyd M. "It isn't just consultants that need a BSc": student experiences of an Intercalated BSc in primary health care. Med Teach. 2005;27(2):164-8.

91. Simoens S, Hurst J. The supply of physician services in OECD countries. Paris, France: OECD, Directorate for Employment, Labour and Social Affairs Group on Health; January 2006. OECD Health Working Papers 21. Available at: http://www.oecd.org/health/health-systems/35987490.pdf. Accessed 28 March 2015.

92. Lumb A, Murdoch-Eaton D. Electives in undergraduate medical education: AMEE Guide No. 88. Med Teach. 2014;36(7):557-72.

93. Grimshaw J, Campbell M, Eccles M, Steen N. Experimental and quasiexperimental designs for evaluating guideline implementation strategies. Fam Pract. 2000;17(suppl 1):S11-16.

94. Ringsted C, Hodges B, Scherpbier A. 'The research compass': an introduction to research in medical education: AMEE Guide no. 56. Med Teach. 2011;33(9):695-709.

95. Lie D, Boker J, Dow E, et al. Attributes of effective community preceptors for pre-clerkship medical students. Med Teach. 2009;31(3):251-9.

96. Bradner M, Crossman SH, Vanderbilt AA, Gary J, Munson P. Career advising in family medicine: a theoretical framework for structuring the medical student/faculty advisor interview. Med Educ Online. 2013;18:21173. doi:10.3402/meo.v18i0.21173. 